\title{
Math-based Spark Ignition Engine Modelling Including Emission Prediction for Control Applications
}

\author{
Hadi Adibi-Asl ${ }^{1}$, Roydon Fraser ${ }^{2}$, John McPhee $^{3}$ \\ 1. Mechanical and Mechatronics Engineering, University of Waterloo, Waterloo, \\ Canada
}

2. Mechanical and Mechatronics Engineering, University of Waterloo, Waterloo, Canada

3. Systems Design Engineering, University of Waterloo, Waterloo, Canada

1. Corresponding author. Email: hadibi@ uwaterloo.ca

2.rafraser@uwaterloo.ca

3. mcphee@real.uwaterloo.ca

1. Hadi Adibi-Asl is currently a postdoctoral researcher at Toyota Motor Manufacturing Canada (TMMC). He has been working on developing efficient physics-based powertrain components such as internal combustion engines and an automatic transmission system for model-based control applications. His research interests are modelling and optimization of dynamic systems, vehicle dynamics, internal combustion engines, and human-process modelling.

2. Roydon A. Fraser is a Professor and Teaching Chair within the Department of Mechanical and Mechatronics Engineering at the University of Waterloo. His research interests focus on energy conversion systems. Fundamental work includes the characterization of spark ignition engine combustion, the integration and control of alternative fuels powertrains into vehicles, and the application of energy and the second law of thermodynamics to the characterization and optimization of complex thermodynamic systems. Dr. Fraser is a recipient of the 2010 National Science Foundation Outstanding Faculty Advisor Award and a DOE Applied Automotive Engineering Fellowship in 2013.

3. John McPhee is a Professor in Systems Design Engineering at the University of Waterloo, Canada, and the Canada Research Chair in Biomechatronic System Dynamics. His main area of research is multibody system dynamics, with principal application to the analysis and design of vehicles, mechatronic devices, biomechanical systems, and sports equipment. He is a Fellow of the American Society of Mechanical Engineers and the Canadian Academy of Engineering. He was the Executive Director of the Waterloo Centre for Automotive Research until 2009, after which he spent a sabbatical year at the Toyota Technical Centre in Ann Arbor, Michigan. 


\section{Math-based Spark Ignition Engine Modelling Including Emission Prediction for Control Applications}

A complete spark ignition (SI) engine model is a multi-domain model including fluid dynamics, thermodynamics, combustion, electrical, and mechanical sub-models. The complexity of these models depends on the type of analysis used for model development, which may vary from highly detailed computational fluid dynamics (CFD) analysis (multi-dimensional model) to simpler data-based analysis in which the data is obtained from experiments (zero-dimensional model).

The main objective of our research is to develop a math-based SI engine model for control application and real time simulation. The model must be accurate enough to capture the combustion characteristics (e.g. combustion temperature) and predict emission gases, while being fast enough for real time simulation purposes.

In this paper, a physics-based model of an SI engine is presented which consists of different sub-models including: throttle body and manifold model, four-stroke quasi-dimensional thermodynamic model of gas exchange and power cycles, two-zone combustion and flame propagation model, emission gases model based on the chemical kinetics equations, and mechanical torque model. Moreover, part of the simulation results is validated against the GTPower simulation results.

The math-based model is created in the MapleSim environment. The symbolic nature of MapleSim significantly shortens the simulation time and also enables parametric sensitivity analysis.

Keywords: spark ignition engine model; two-zone combustion; quasidimensional modelling; emission prediction; real-time simulation

\section{Introduction}

Today, automobile manufacturers are moving towards more and more virtual vehicle prototypes, including prototypes of the powertrain. A virtual prototype facilitates the modeling and simulation of a physical (real) prototype in a software environment (virtual domain). The main advantages of simulating virtual prototypes before making physical prototypes are:

- Lower expenses: the cost of making a virtual prototype is less than the physical prototype. 
- Higher quality: virtual prototypes enable the rapid virtual testing of many iterations to study the effect of parameter changes on a design, thus improving the quality of the physical prototype when constructed.

The main objective of our research is to develop a math-based SI engine model for control application and real time simulation. The model must be accurate enough to capture the combustion characteristics (e.g. combustion temperature) and predict emission gases, while being fast enough for real time simulation purposes. The mathbased model is created in the MapleSim environment [1]. The advantages of using the MapleSim environment to build the engine model are:

- The symbolic nature of MapleSim in modeling significantly reduces the simulation time, which makes the model suitable for control study and real time simulation.

- The model can be integrated with the rest of the powertrain (e.g. transmission), or the complete vehicle, through acausal connections for powertrain simulation.

SI engines have been modelled in different ways based on the level of the model complexity. For instance, the SI engine characteristics can be expressed by a group of look-up tables, or simple torque-speed differential equations, or a more detailed model with chemical reactions and fluid dynamics. The level of complexity of the model in this study is defined such that it predicts in-cylinder thermodynamic properties (e.g. pressure, burned and unburned temperature), emission gases, and mechanical torque, while having real time simulation performance.

A quasi-dimensional approach, using a two-zone combustion model, is used in this study to model a four-stroke engine. The schematic diagram in Figure 1 depicts the main inputs, outputs, and sub-models. The main sub-models which are discussed in this paper are the single cylinder model and emission model. The throttle body and manifold sub-model is similar to the model developed by Saeedi [2]. The main inputs to the cylinder sub-model are the air/fuel mixture, which is delivered from intake manifold, spark timing, which is fed to the model as a constant angle (e.g. 30 degrees before top dead centre) at each cycle, and the engine rotational speed (rpm). The desired outputs of the model are torque delivered to the transmission shaft, and emission gases.

In the next section, we describe previous work on SI engine modelling, in order to establish the novelty of the current work. 
The details of the sub-models, including two-zone combustion, output torque, and emission gases, are discussed in the following sections.

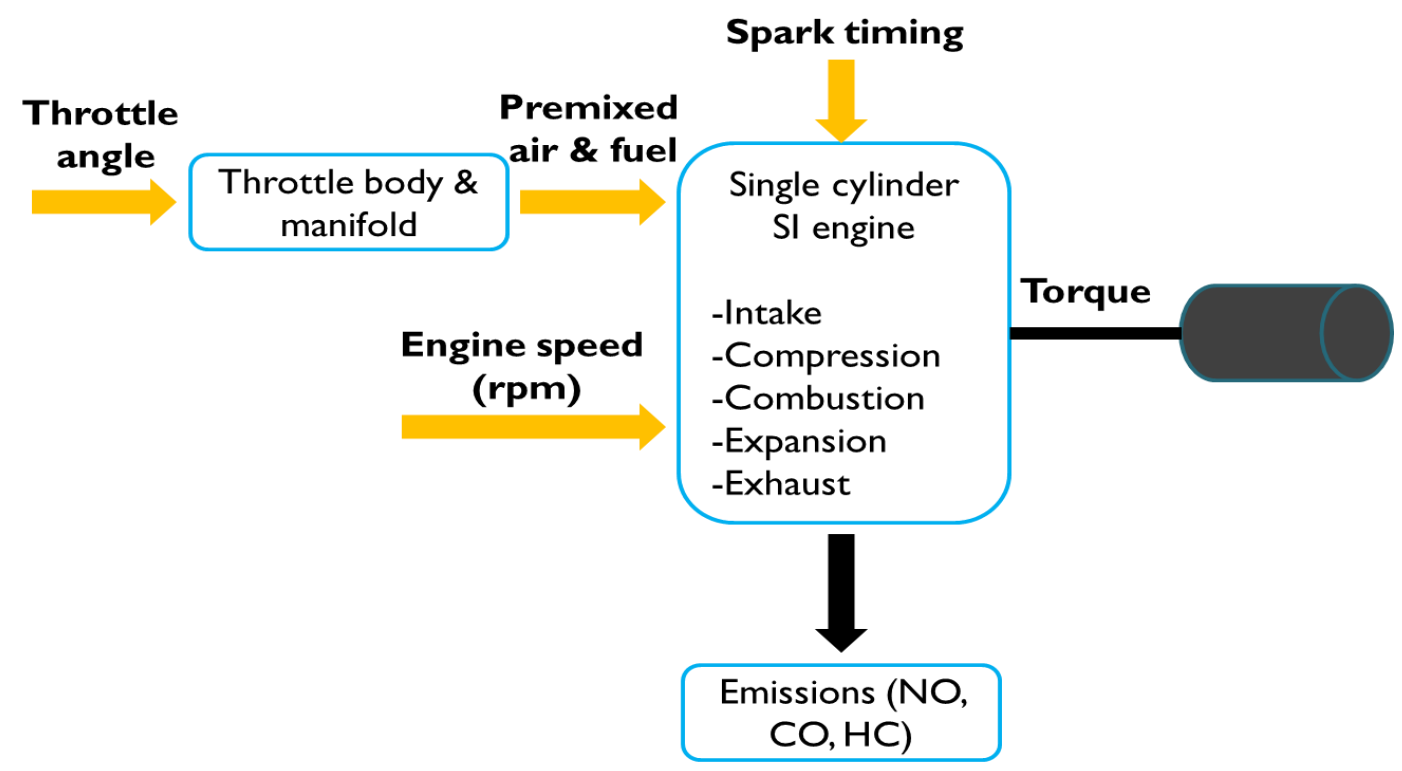

Figure 1: Schematic diagram of SI engine sub-models

\section{Background}

The mean-value engine model (MVEM), which is widely used in model-based control applications [2], is partially a physics-based SI engine model. However, detailed physical phenomena such as the combustion model, including fuel chemical kinetics, and the emission model cannot be represented by the MVEM.

Combustion in SI engines is the complex phenomenon which directly affects the fuel consumption, emission gases, and powertrain vibration. The combustion in the SI engine happens just before the end of the compression stroke, extends through the combustion stroke, and ends after the peak cylinder pressure occurs [3].

Mathematical models of spark ignition engines, from a thermodynamics point of view, can be categorized into single zone and multi-zone models. In the single zone model, the fuel composition, temperature, and pressure are assumed to be uniform in the cylinder. The multi-zone model is a more realistic model which contains the burned and unburned regions [4]. Considering more zones in the combustion chamber increases the number of calculations, but the results are more realistic, specifically when evaluating the formation of emissions [5], [6], and [7]. 
In multi-zone models (e.g. two zones) the combustion chamber is divided into burned and unburned zones. Each zone has different properties in terms of composition, temperature, and pressure distribution. Essentially the governing equations are based on conservation of mass and energy which are used to calculate the cylinder thermodynamic state variables (e.g. cylinder pressure) [4]. The two-zone thermodynamic assumptions and mathematical derivations are presented in the next section.

Benson et al. [8] studied a comprehensive simulation model of a four-stroke SI engine model. The proposed model simulated a full power cycle and gas dynamic model in the exhaust pipe. Moreover, the simulations can predict $N O_{x}$ emissions. In their work, a two-zone combustion model is employed to simulate the ignition (expansion) stroke. Equations of each stroke (e.g. compression, ignition, and expansion) are derived and combustion kinetics is used to model $N O_{x}$ emissions along the exhaust pipe. The simulation results show good agreement with experimental results.

Blumberg et al [9] were among the first researchers that presented a physics-based SI engine model. They described the SI engine complex structure as a group of separate physically-based sub-models that are phenomenologically important. In other words, the sub-models are presented based on fundamental physical formulations (e.g. conservation of mass and energy) in a suitable way that can depict the phenomena in the proposed sub-model. However, the model is not able to predict full emission gases and simulate many cycles scenario.

Bayraktar [10] and Bayraktar and Durgun [11] developed a quasi-dimensional SI engine cycle with a combustion model as a flame propagation process. The model is based on a two-zone combustion model, and all four strokes are mathematically formulated. The pressure and temperature variations of the proposed math-based model show good agreement with the experimental results for different engines (e.g. Figure 2 compares the theoretical pressure variation with experiments). Although their math-based SI engine model can well predict power, temperature, and pressure in a cylinder, it could not predict emissions (no chemical kinetics is included in the model). 


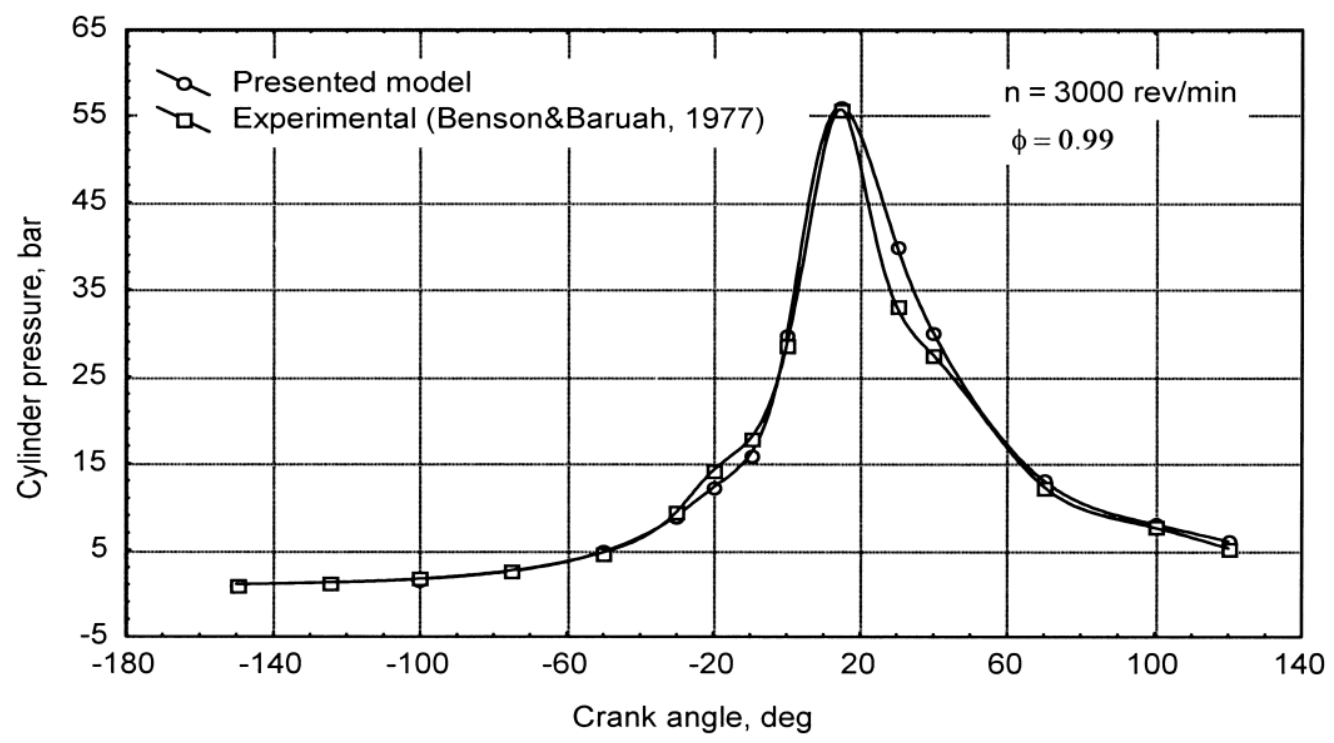

Figure 2: Pressure variations of the math-based model vs. experimental results [10]

Verhelst and Sheppard [12] presented a critical overview of SI engine combustion modeling using a multi-zone approach. The authors mentioned that choosing a multizone, also called quasi-dimensional, or multi-dimensional model is largely dictated by the applications of the proposed engine model. For instance, if the goal of the SI engine model is to simulate the engine characteristics in a wide range of operation and to evaluate the effect of engine parameters on the engine performance with a reasonable level of accuracy and fast computational time, then a multi-zone model is recommended.

Math-based two-zone SI engine combustion models have been simulated in Matlab/Simulink [13] and Modelica/Dymola [14]. The combustion models, in these works, include physical and thermodynamic formulations to simulate the generated power, but they do not include an integrated model of combustion chemical kinetics to predict emissions.

In this current paper, we use a similar approach to that of Bayraktar [10] to model the two-zone combustion thermodynamics. An emission model based on equilibrium concentrations and free Gibbs energy calculations is simulated along with the thermodynamics model at each time step. The thermodynamic sub-model and emission sub-model are tightly integrated and simulated simultaneously. The whole SI engine model is built in the MapleSim software, which has a multi-domain environment, so that the engine model can be connected to the rest of the powertrain for model-based powertrain or vehicle control. 


\section{Two-zone SI Engine Model}

In a two-zone approach, the combustion chamber is split into "burned" and "unburned" zones [4]. The flame propagation (entrained zone) is moving from burned toward unburned zone during combustion as shown in Figure 3.

The advantage of using a physics-based two-zone combustion approach is achieving better fidelity, in comparison with zero-dimensional approach, while having fast simulation time for many cycles simulation.
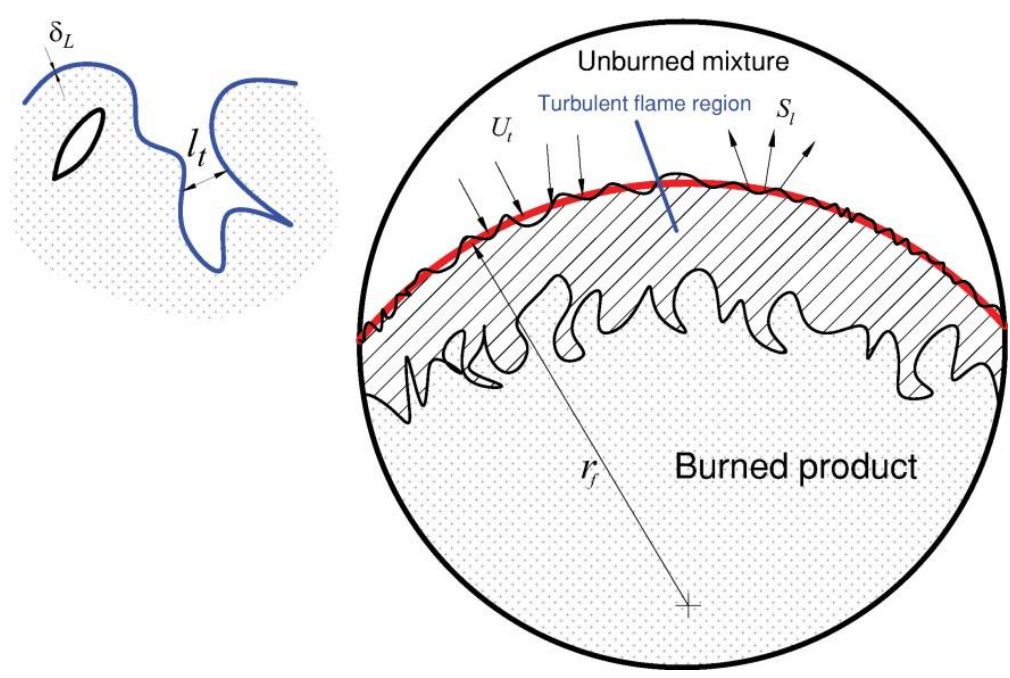

Figure 3: Schematic of two-zone combustion chamber

The main assumptions used to model a two-zone combustion SI engine in this paper are:

- The intake and exhaust strokes are isentropic processes.

- The compression and expansion strokes are modelled based on the first thermodynamic law as a single zone model.

- The pressure distribution is uniform inside the cylinder during each stroke.

- The combustion process is modelled based on the turbulent flame propagation theory in addition to the first law of thermodynamics.

- The flame front shape is assumed to be spherical. However, the flame thickness (volume) is assumed small in comparison with burned and unburned zones.

- During the combustion, each zone has a uniform composition and temperature.

- The burned/unburned gases are considered as ideal gases.

The whole cycle simulation is described by Figure 4. The intake stroke starts when the piston goes from top-dead-centre (TDC) of the cylinder to the bottom-dead-centre 
(BDC). Then, the simulation switches to the compression stroke from BDC to some angle close to the next TDC.

The combustion process is started when the spark plug is ignited until the total mass is burned. The burned duration $(B D)$, as a fraction of crank angle, is empirically defined for the model used in this research by Eq. (1) [15]. In this equation, $C R, n, \varphi$, and $S A$ represent compression ratio, engine speed, equivalence ratio, and spark advance angle in degrees, respectively.

$B D^{o}=$

$\left(3.2989-3.3612(C R / 7.5)+1.08(C R / 7.5)^{2}\right)(0.1222+0.9717(n / 1000)-$

$\left.0.0505(n / 1000)^{2}\right)\left(4.311-5.6383(\varphi)+2.3040(\varphi)^{2}\right)\left(1.068+0.290\left(S A^{o} / 30\right)+\right.$

$\left.0.2545\left(S A^{o} / 30\right)^{2}\right)$

The expansion stroke starts at the end of the combustion process and finishes when the piston reaches the BDC. Finally, the exhaust valve is opened and the piston moves from BDC to TDC and the exhaust gases are driven out through the exhaust valve.

The detailed formulations of thermodynamic equations and flame propagation model are given by Bayraktar [10].

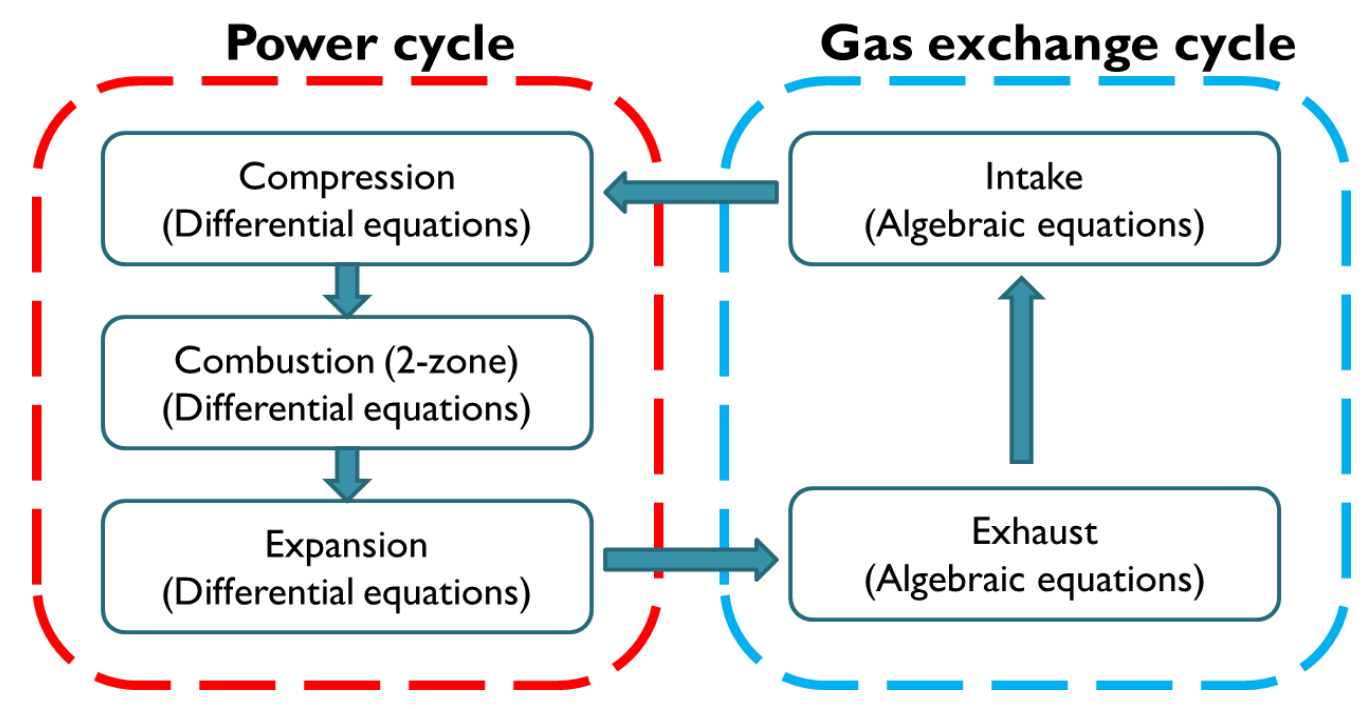

Figure 4: Cycle simulation procedure

The output torque $\left(\tau_{\text {cycle }}\right)$ is calculated based on the in-cylinder pressure $\left(P_{\text {net }}\right)$ and geometrical parameters (Eq. (2)) including in-cylinder instantaneous volume $(V)$, rod length, crank radius, and crank angle $(\theta)$ [16]. The schematic diagram, shown in Figure 5 , depicts the equilibrium calculation of output torque from cylinder geometry and in- 
cylinder thermodynamic pressure. The mass of the piston, rod, and crankshaft are assumed to be negligible in comparison to the load.

$\tau_{\text {cycle }}=\left(P_{\text {net }}\right)(V)\left(^{\sin (\gamma+\theta)} / 2 \cos \gamma\right)$

Where:

$\gamma=\arcsin [($ Stroke $/ 2 \operatorname{Rod}) \sin \theta]$

$V=A_{p} \times$ Stroke

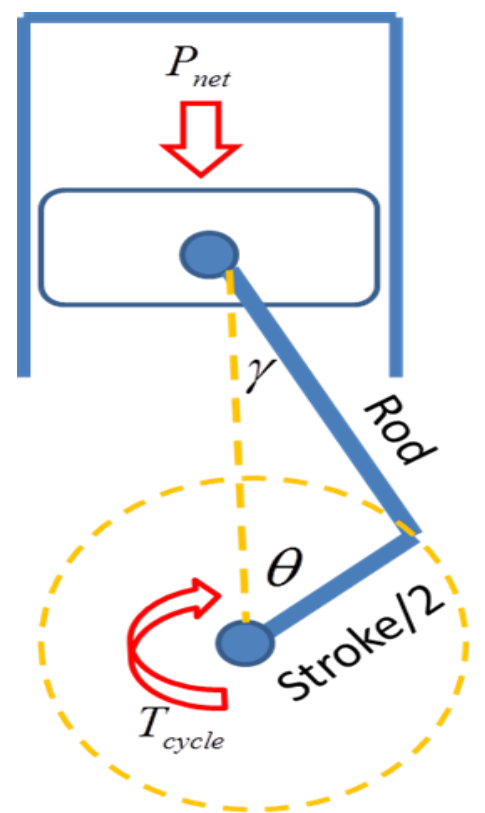

Figure 5: Schematic diagram of in-cylinder pressure and torque

\section{Emission Model}

The emission sub-model, which is created along with the two-zone combustion model, takes the in-cylinder pressure, burned temperature, and volume as inputs and calculates the emission gases (e.g. $N O$ and $\mathrm{CO}$ ). The emission calculation procedure is shown in Figure 6. 


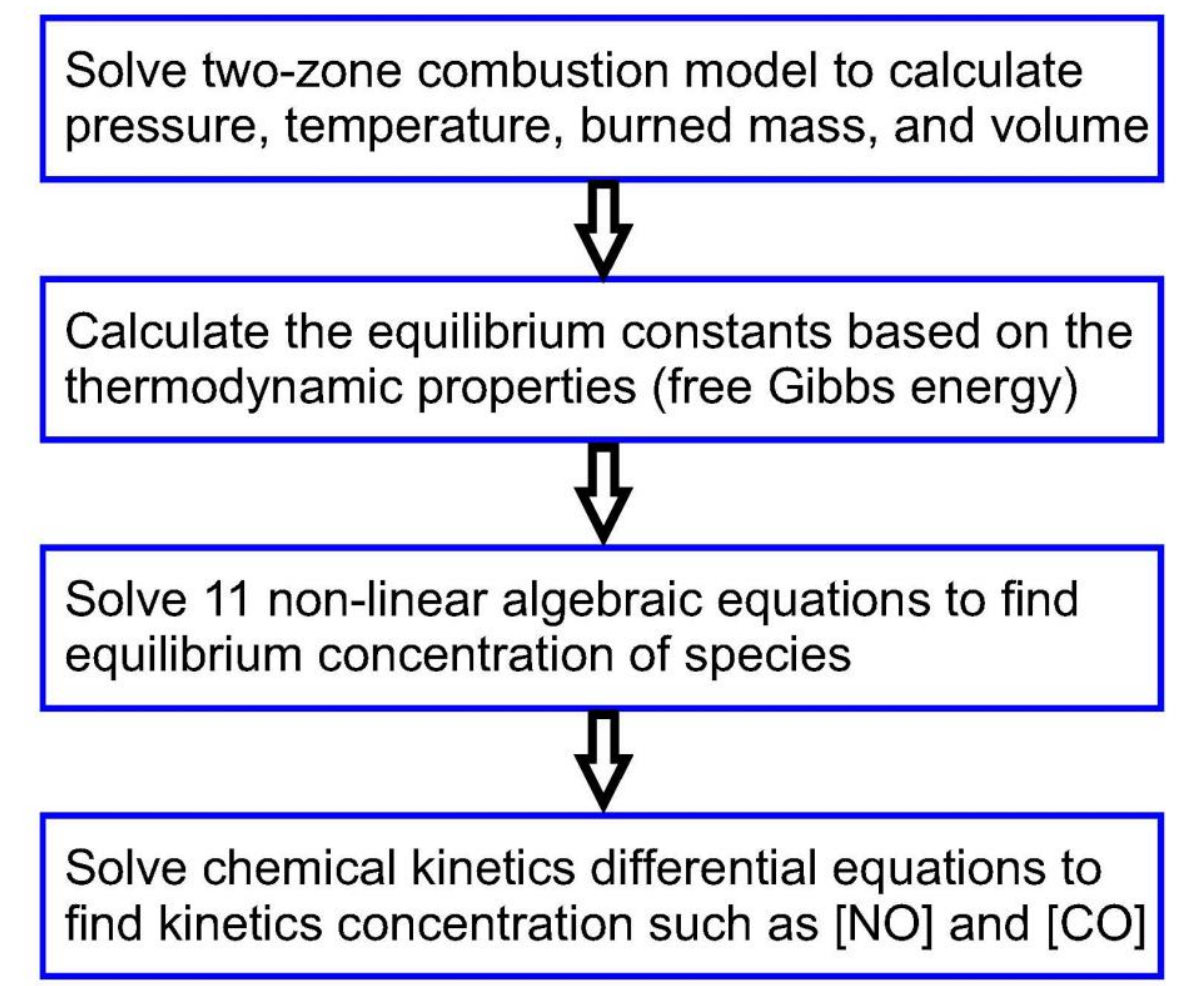

Figure 6: Emission calculation procedure

The general formulation of air and fuel reaction is shown in Eq. (3), where $\alpha$ and $\beta$ represent the type of hydrocarbon fuel, $a$ is given by Eq. (4), and $\varphi$ is the equivalence ratio (the ratio between stoichiometric and actual air-fuel ratio).

$$
\begin{aligned}
& \mathrm{C}_{\alpha} \mathrm{H}_{\beta}+\mathrm{a}\left(\mathrm{O}_{2}+3.76 \mathrm{~N}_{2}\right) \rightarrow n_{\mathrm{CO}_{2}} \mathrm{CO}_{2}+n_{\mathrm{CO}} \mathrm{CO}+n_{\mathrm{H}_{2} \mathrm{O}} \mathrm{H}_{2} \mathrm{O}+n_{\mathrm{H}_{2}} \mathrm{H}_{2}+n_{\mathrm{H}} \mathrm{H}+ \\
& n_{\mathrm{OH}} \mathrm{OH}+n_{\mathrm{N} 2} \mathrm{~N}_{2}+n_{\mathrm{NO}} \mathrm{NO}+n_{\mathrm{N}} \mathrm{N}+n_{\mathrm{O} 2} \mathrm{O}_{2}+n_{\mathrm{O}} \mathrm{O} \\
& a=(4 \alpha+\beta) / 4 \varphi
\end{aligned}
$$

The products of the reaction are eleven species, and the coefficients $n_{i}$ represent the number of moles of each species during the reaction [17].

The eleven emission species are assumed in equilibrium, so four atom balance and seven equilibrium reaction equations are derived to calculate the equilibrium species at each time step.

The four atom balance equations for $C, H, O$, and $N$ are listed in the set of equations in Eq. (5).

$C: \quad \alpha=n_{\mathrm{CO} 2}+n_{\mathrm{CO}}$

$H: \quad \beta=2 n_{H 2 O}+2 n_{H 2}+n_{H}+n_{O H}$

$O: \quad 2 a=2 n_{C O 2}+n_{C O}+n_{H 2 O}+n_{O H}+n_{N O}+2 n_{O 2}+n_{O}$

$N: \quad 7.52 a=2 n_{N 2}+n_{N O}+n_{N}$ 
The seven equilibrium reactions are shown in Eq. (6), where the molar fraction of each species, in the equilibrium reactions, is represented by $X_{i}=n_{i} / n_{\text {Total }}$. The $K p_{i}$ represents the equilibrium constant of the $i^{\text {th }}$ equilibrium reaction. The equilibrium constant is calculated based on the Gibbs free energy and combustion temperature (Eq. (7)). $P$ and $P_{0}$ are in-cylinder pressure at each time step and ambient (reference) pressure respectively, where $P_{\text {net }}=P-P_{0}$.

$$
\begin{aligned}
& H_{2} \leftrightarrow H+H \quad X_{H}=\sqrt{K_{p 1} / P / P_{0}} \sqrt{X_{H 2}} \\
& O_{2} \leftrightarrow O+O \quad X_{O}=\sqrt{K_{p 2} / P / P_{0}} \sqrt{X_{O 2}} \\
& N_{2} \leftrightarrow N+N \quad X_{N}=\sqrt{K_{p 3} / P / P_{0}} \sqrt{X_{N 2}} \\
& H_{2} O \leftrightarrow H_{2}+0.5 O_{2} \quad X_{H 2}=K_{p 4} / \sqrt{P / P_{0}} X_{H 2 O} / \sqrt{X_{O 2}} \\
& H_{2} O \leftrightarrow 0.5 H_{2}+O H \quad X_{O H}=K_{p 5} / \sqrt{P / P_{0}} X_{H 2 O} / \sqrt{X_{H 2}} \\
& C_{2} \leftrightarrow C O+0.5 O_{2} \\
& 0.5 O_{2}+0.5 N_{2} \leftrightarrow N O \quad X_{C O}=K_{p 6} / \sqrt{P / P_{0}} / \sqrt{X_{O 2}}
\end{aligned}
$$

The specific Gibbs energy, a property of each species, varies with the burned temperature $\left(T_{b}\right)$. Therefore, the specific Gibbs energy values of the eleven species are modelled as a group of look-up tables based on physical properties [17].

$K_{p i}=\exp \left(-\Delta G i / T_{R} T_{b}\right) \quad i=1,2, \ldots, 7$

The equilibrium concentration of each species at each time step is calculated by solving four algebraic atom balance and seven nonlinear algebraic equilibrium concentration equations. Then, the well-known extended Zeldovich mechanism is employed to calculate the kinetic concentration of $N O$ (Eq. (8)), and a similar formulation is derived in [18] for $C O$ (Eq. (9)), where $V_{b}$ represents the burned volume of the mixture. 
$1 / V_{b} d[N O] / d t=2 \Gamma_{1}\left(1-\left([N O] / X_{N O}\right)^{2}\right) / 1+\left([N O] / X_{N O}\right)\left(\Gamma_{1} / \Gamma_{2}+\Gamma_{3}\right)$

Where:

$$
\begin{aligned}
& \Gamma_{1}=7.6 \times 10^{13} \exp \left(-38000 / T_{b}\right) X_{O} X_{N 2} \\
& \Gamma_{2}=1.5 \times 10^{9} \exp \left(-19500 / T_{b}\right) X_{N O} X_{O} \\
& \Gamma_{3}=2 \times 10^{14} \exp \left(-23650 / T_{b}\right) X_{N O} X_{H}
\end{aligned}
$$

$$
1 / V_{b} d[\mathrm{CO}] / d t=\left(\Gamma_{4}+\Gamma_{5}\right)\left(1-[\mathrm{CO}] / X_{C O}\right)
$$

Where:

$$
\begin{aligned}
& \Gamma_{4}=6.76 \times 10^{10} \exp \left(T_{b} / 1102\right) X_{C O} X_{O H} \\
& \Gamma_{5}=2.5 \times 10^{12} \exp \left(-24055 / T_{b}\right) X_{C O} X_{O 2}
\end{aligned}
$$

\section{Symbolic Sensitivity Analysis}

This section presents symbolic sensitivity analysis of a single cylinder SI engine model. Sensitivity analysis is the study of the model's parameters, and their effect on the model outputs or performance. Cylinder design parameters such as bore, stroke, and compression ratio, play an important role to achieve higher performance (e.g. power) and reduce undesirable in-cylinder phenomenon (e.g. knocking).

The set of DAEs is expressed in Eq. (10), and a dynamic sensitivity equation is derived in Eq. (11), where $X$ and $\xi$ represent state variable and design parameter. $\boldsymbol{S}_{j}^{X}$ is the vector representing the sensitivity functions of the a state variable with respect to the $j^{\text {th }}$ parameter. The symbolic sensitivity equations are generated in Maple worksheet, and then the sensitivity equations are integrated with the two-zone combustion model. The whole DAEs are solved at each crank angle with the stiff solver, Rosenbrock, in the MapleSim environment. 
$\sum:\left\{\begin{array}{c}\dot{\boldsymbol{X}}(t, \xi)=\boldsymbol{f}(t, \boldsymbol{X}, \xi) \quad, \boldsymbol{X}(\mathbf{0}, \xi)=\boldsymbol{X}_{\mathbf{0}} \\ \boldsymbol{g}(t, \boldsymbol{X}, \xi)=\mathbf{0}\end{array}\right.$

$$
\dot{\boldsymbol{S}}_{j}^{X}=\left(\frac{\partial \boldsymbol{f}}{\partial X}\right) \boldsymbol{S}_{j}^{X}+\left(\frac{\partial f}{\partial \xi_{j}}\right)
$$

The parameters of the two-zone combustion model are listed in Table 1, and the sensitivity functions of the state variables are generated with respect to the bore diameter and stroke length. The nominal value of the bore diameter $(\bar{B})$ and the stroke length $(\bar{L})$ are $0.085 \mathrm{~m}$ and $0.1 \mathrm{~m}$ respectively. By changing the nominal values, the new sensitivity functions must be regenerated. In other words, the sensitivity function simulation result is only valid for the specific values of the bore diameter and stroke length.

Since the pressure, burned temperature, and unburned temperature are all nonlinear first order differential equations, the corresponding sensitivity functions of the new states are integrated with the flame propagation sensitivity functions $\left(\boldsymbol{S}_{j}^{x}\right)$ to symbolically generate the sensitivity graphs of the DAEs (Eq. (12)). Figure 7 and Figure 8 represent the solution of the sensitivity equations of the in-cylinder pressure with respect to the bore diameter and stroke length. The peak pressure during the combustion process is very sensitive to both the bore diameter and stroke length. The total mass inside the combustion chamber is constant during the combustion process. Therefore by increasing the combustion chamber volume, the peak pressure drops at the same operating conditions (Figure 9).

$$
\left(\begin{array}{c}
\dot{\boldsymbol{S}}_{j}^{m e} \\
\dot{\boldsymbol{S}}_{j}^{m b} \\
\dot{\boldsymbol{S}}_{j}^{P} \\
\dot{\boldsymbol{S}}_{j}^{T b} \\
\dot{\boldsymbol{S}}_{j}^{T u}
\end{array}\right)=\left(\begin{array}{lllll}
\frac{\partial f^{m e}}{\partial m_{e}} & \frac{\partial f^{m e}}{\partial m_{b}} & \frac{\partial f^{m e}}{\partial P} & \frac{\partial f^{m e}}{\partial T_{b}} & \frac{\partial f^{m e}}{\partial T_{u}} \\
\frac{\partial f^{m b}}{\partial m_{e}} & \frac{\partial f^{m b}}{\partial m_{b}} & \frac{\partial f^{m b}}{\partial P} & \frac{\partial f^{m b}}{\partial T_{b}} & \frac{\partial f^{m b}}{\partial T_{u}} \\
\frac{\partial f^{P}}{\partial m_{e}} & \frac{\partial f^{P}}{\partial m_{b}} & \frac{\partial f^{P}}{\partial P} & \frac{\partial f^{P}}{\partial T_{b}} & \frac{\partial f^{P}}{\partial T_{u}} \\
\frac{\partial f^{T b}}{\partial m_{e}} & \frac{\partial f^{T b}}{\partial m_{b}} & \frac{\partial f^{T b}}{\partial P} & \frac{\partial f^{T b}}{\partial T_{b}} & \frac{\partial f^{T b}}{\partial T_{u}} \\
\frac{\partial f^{T u}}{\partial m_{e}} & \frac{\partial f^{T u}}{\partial m_{b}} & \frac{\partial f^{T u}}{\partial P} & \frac{\partial f^{T u}}{\partial T_{b}} & \frac{\partial f^{T u}}{\partial T_{u}}
\end{array}\right)\left(\begin{array}{c}
\boldsymbol{S}_{j}^{m e} \\
\boldsymbol{S}_{j}^{m b} \\
\boldsymbol{S}_{j}^{P} \\
\boldsymbol{S}_{j}^{T b} \\
\boldsymbol{S}_{j}^{T u}
\end{array}\right)+\left(\begin{array}{c}
\frac{\partial f^{m e}}{\partial \xi_{j}} \\
\frac{\partial f^{m b}}{\partial \xi_{j}} \\
\frac{\partial f^{P}}{\partial \xi_{j}} \\
\frac{\partial f^{T b}}{\partial \xi_{j}} \\
\frac{\partial f^{T u}}{\partial \xi_{j}}
\end{array}\right)
$$




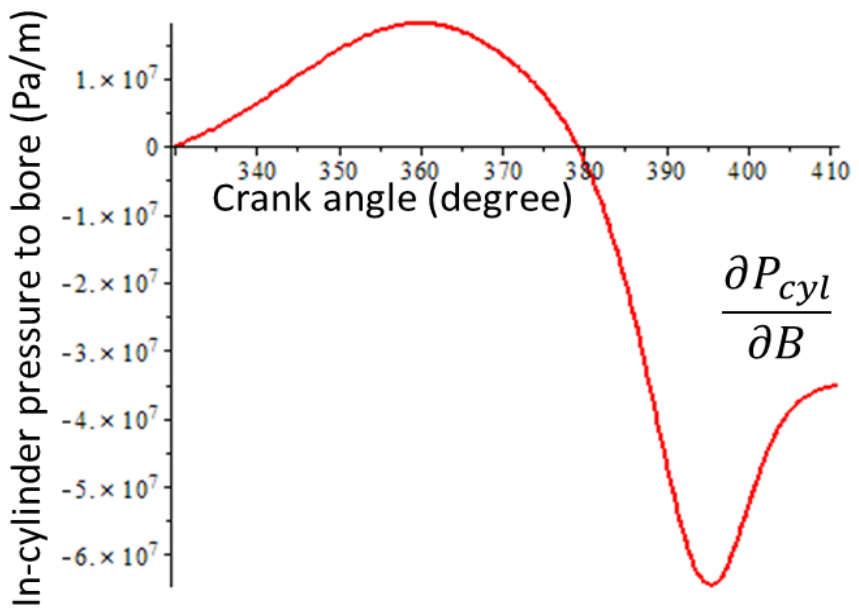

Figure 7: In-cylinder pressure sensitivity with respect to bore diameter

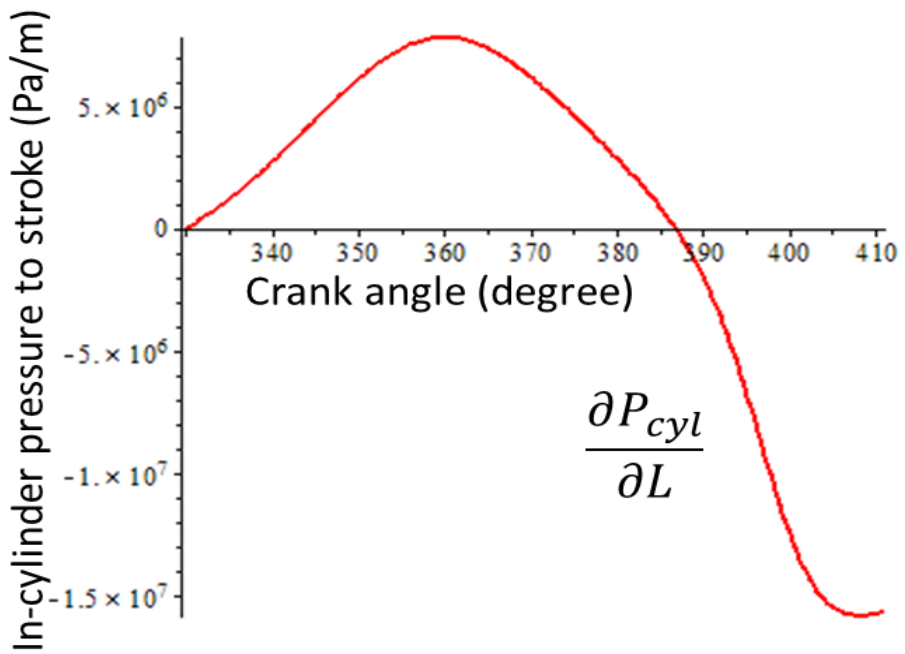

Figure 8: In-cylinder pressure sensitivity with respect to stroke length

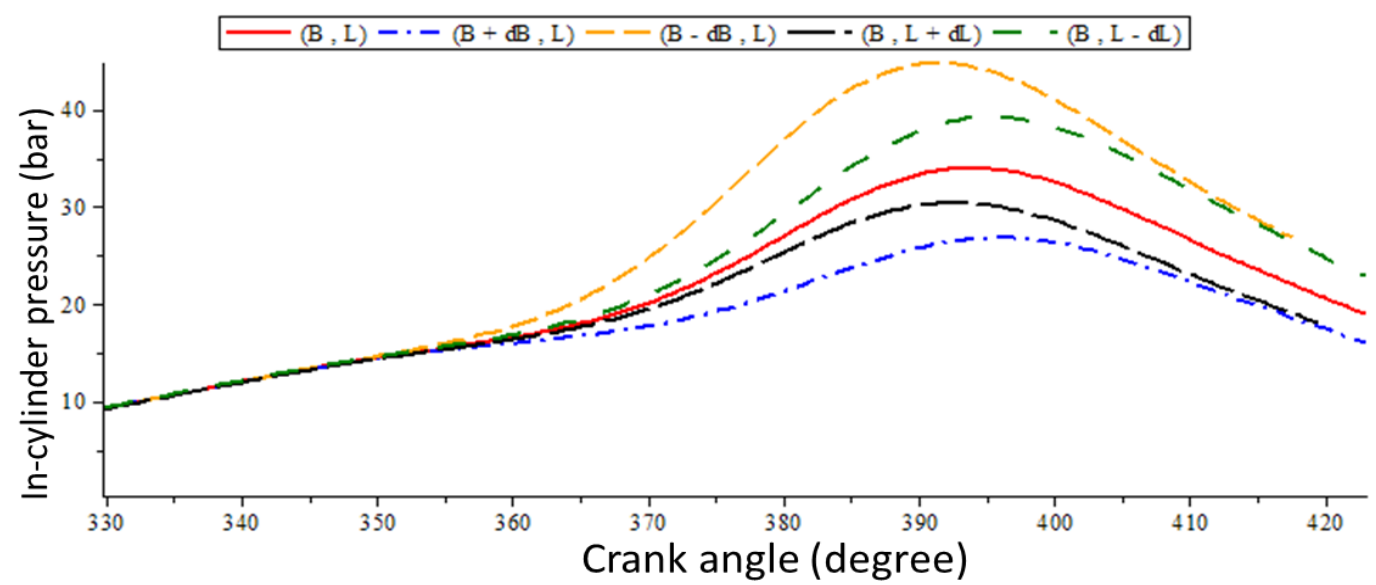

Figure 9: In-cylinder pressure variations for different perturbations from the nominal values

A similar approach, to that used to generate turbulent flame speed sensitivity function, is employed to derive mechanical torque sensitivity with respect to the design 
parameters (Eq. (13)) and Figure 10 and Figure 11. The plots in Figure 12 show that the torque variation during the combustion process is not as sensitive as the in-cylinder pressure. The main reason is that the mechanical torque is proportional to product of the in-cylinder pressure and volume at each crank angle. Therefore by increasing either the bore diameter or stroke length, the peak pressure drops and the combustion chamber volume increases.

$$
\partial \tau / \partial \xi_{j}=\left(\frac{\partial \boldsymbol{f}^{\tau}}{\partial P_{C y l}}\right) \boldsymbol{S}_{j}^{P}+\left(\frac{\partial \boldsymbol{f}^{\tau}}{\partial \xi_{j}}\right)
$$

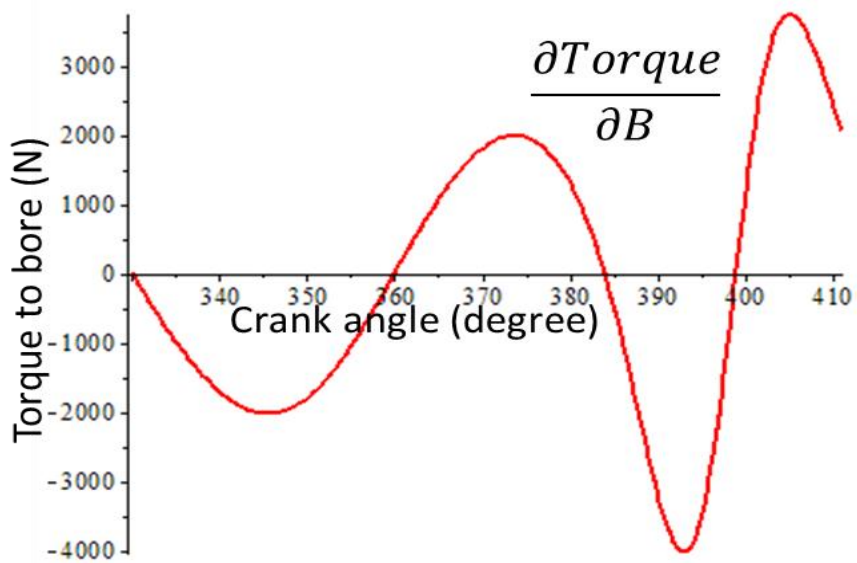

Figure 10: Mechanical torque sensitivity with respect to bore diameter

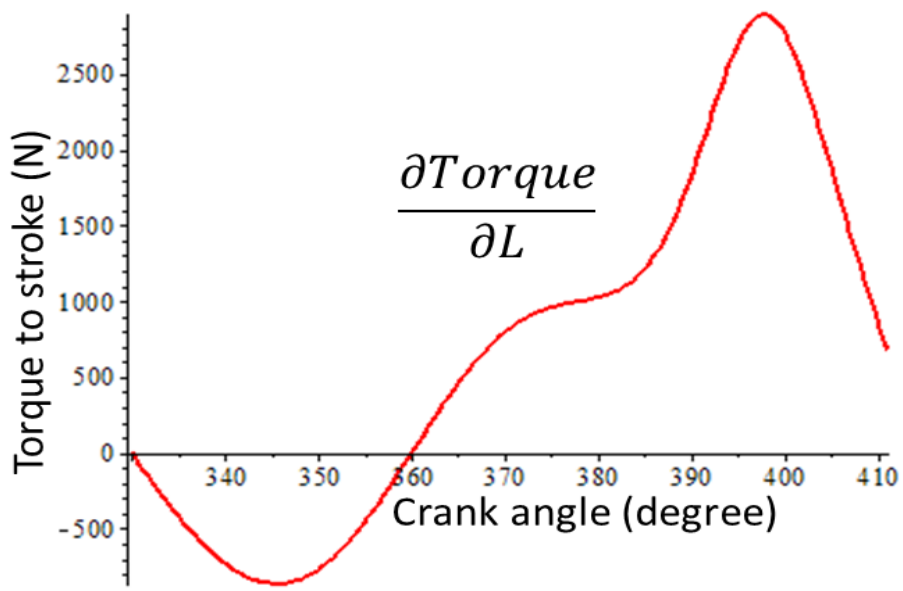

Figure 11: Mechanical torque sensitivity with respect to stroke length 


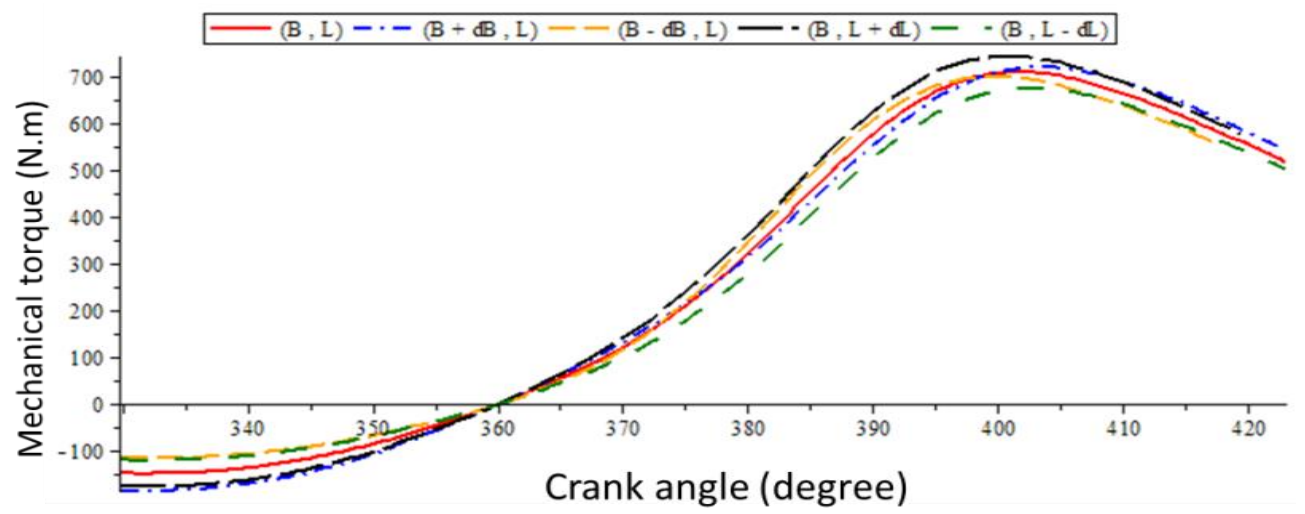

Figure 12: Mechanical torque variations for different perturbations from the nominal values

\section{Simulation Results}

The integrated two-zone combustion and emission models are simulated for one full cycle (720 degrees of crank angle). The single cylinder parameter values, as well as fuel properties, are provided in Table 1.

Table 1: SI engine model parameters and values

\begin{tabular}{|l|l|l|l|}
\hline $\begin{array}{l}\text { Fuel } \\
\left(C_{\alpha} H_{\beta}\right)\end{array}$ & $\alpha=8, \beta=18$ & Rod length & $0.165[\mathrm{~m}]$ \\
\hline $\begin{array}{l}\text { Equivalence ratio } \\
(\varphi)\end{array}$ & 1 & Bore diameter & $0.085[\mathrm{~m}]$ \\
\hline $\begin{array}{l}\text { Gas universal constant } \\
(R)\end{array}$ & $\begin{array}{l}8.314 \\
{\left[\mathrm{~J} .(\mathrm{mol} . \mathrm{K})^{-1}\right]}\end{array}$ & $\begin{array}{l}\text { Compression ratio } \\
(\mathrm{CR})\end{array}$ & 10 \\
\hline $\begin{array}{l}\text { Ambient pressure } \\
\left(P_{0}\right)\end{array}$ & $1[\mathrm{bar}]$ & Engine speed & $\begin{array}{l}3000 \\
{[\mathrm{rpm}]}\end{array}$ \\
\hline $\begin{array}{l}\text { Ambient temperature } \\
\left(T_{0}\right)\end{array}$ & $293[\mathrm{~K}]$ & $\begin{array}{l}\text { Spark advance } \\
(\mathrm{SA})\end{array}$ & $-30[\mathrm{deg}]$ \\
\hline $\begin{array}{l}\text { Cylinder wall } \\
\text { temperature }\left(T_{w}\right)\end{array}$ & $473[\mathrm{~K}]$ & $\begin{array}{l}\text { Total in-cylinder mixture } \\
\text { mass }\end{array}$ & $\begin{array}{l}0.0005 \\
{[\mathrm{~kg}]}\end{array}$ \\
\hline Stroke length & $0.1[\mathrm{~m}]$ & $\begin{array}{l}\text { Average heat capacity } \\
\text { ratio }(\kappa)\end{array}$ & 1.35 \\
\hline
\end{tabular}

The instantaneous (swept) volume during four-stroke operation is shown in Figure 13. The curves are identical, since the swept volume is just function of the engine geometries and rotational speed. 


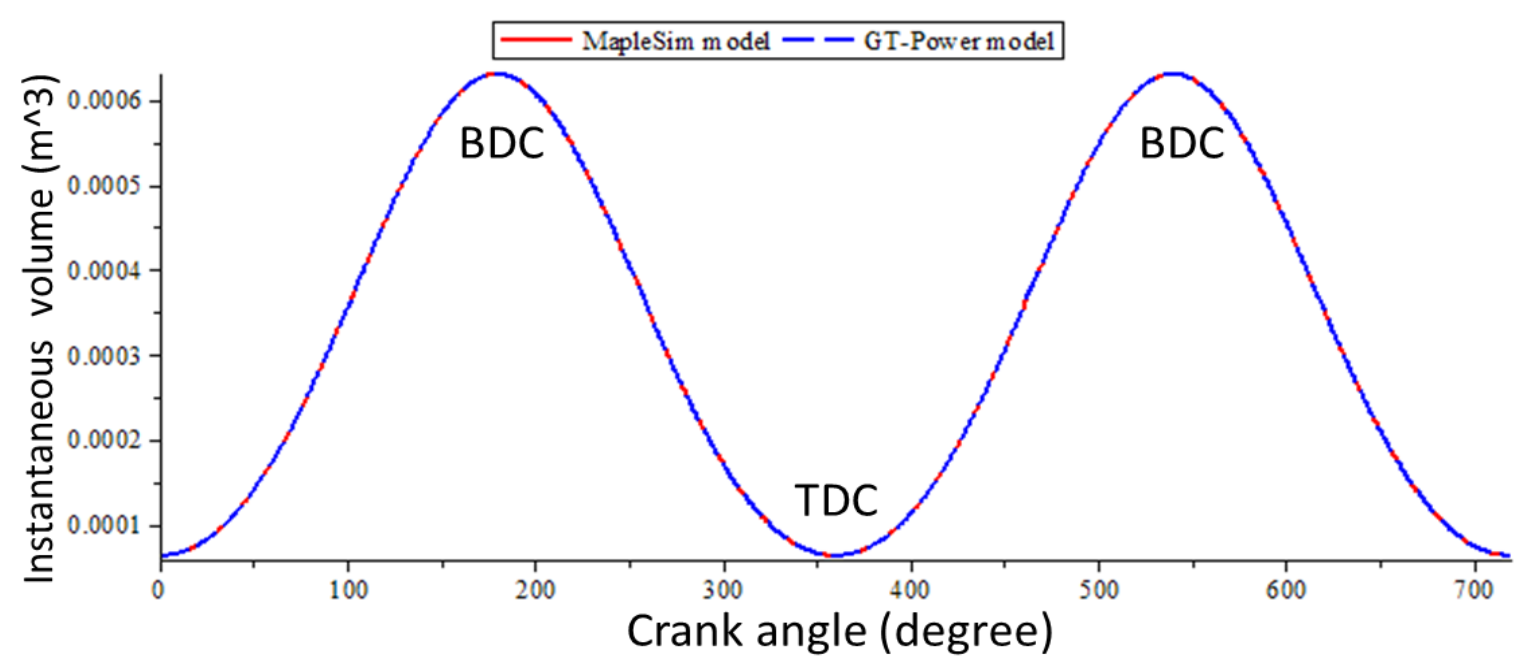

Figure 13: Instantaneous volume during four-stroke operation

The simulation is executed in the GT-Power environment with the same parameter values and engine speed. The models in the GT-Power software are calibrated and validated with experimental results. Therefore, GT-Power can be used as a reliable reference for engine validation purposes. The spark ignition engines in GT-Power are modelled using a two-zone quasi-dimensional approach, which is similar to the modelling method used in this paper. However, GT-Power does not provide the system's physics-based equations. On the other hand, MapleSim generates symbolic equation from a physical model and provides suitable tools for equations manipulation such as symbolic sensitivity analysis, optimization, and model order reduction.

Figure 14 represents the in-cylinder pressure a during four-stroke operation in GTPower software. The trend of in-cylinder pressure as well as peak pressure in both MapleSim and GT-Power models shows a good agreement. However, there are some differences due to the empirical parameters that are tuned differently in both models. 


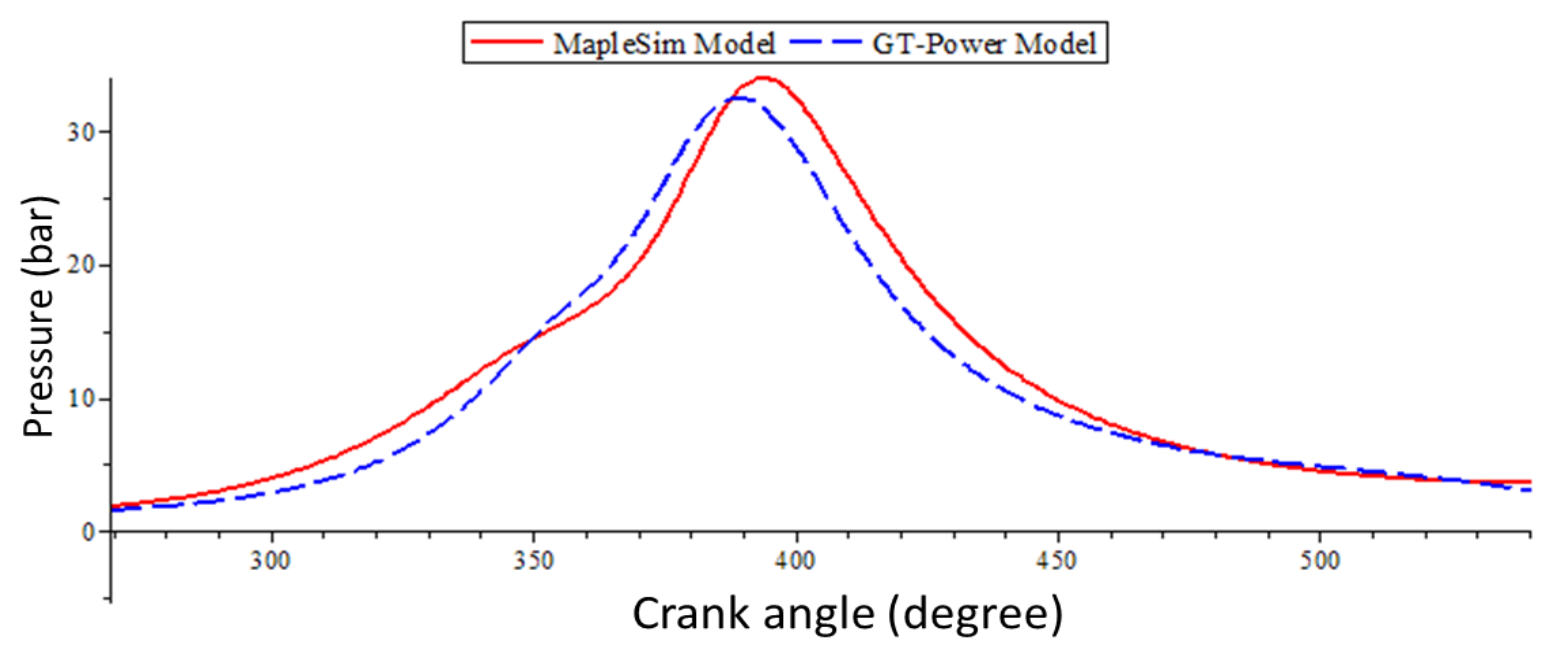

Figure 14: In-cylinder pressure variation during compression and power stroke (MapleSim vs. GT-Power)

The burned temperature is defined from start of the combustion process to the end of exhaust stroke, and the total mixture is fully burned at the end of the combustion process (Figure 15). The temperature rise during the combustion, the trend of the curve during the power stroke, and the exhaust temperature are fairly compatible to the GTPower simulation result. However, there are some errors due to the differences in the pressure variation and the heat transfer rate.

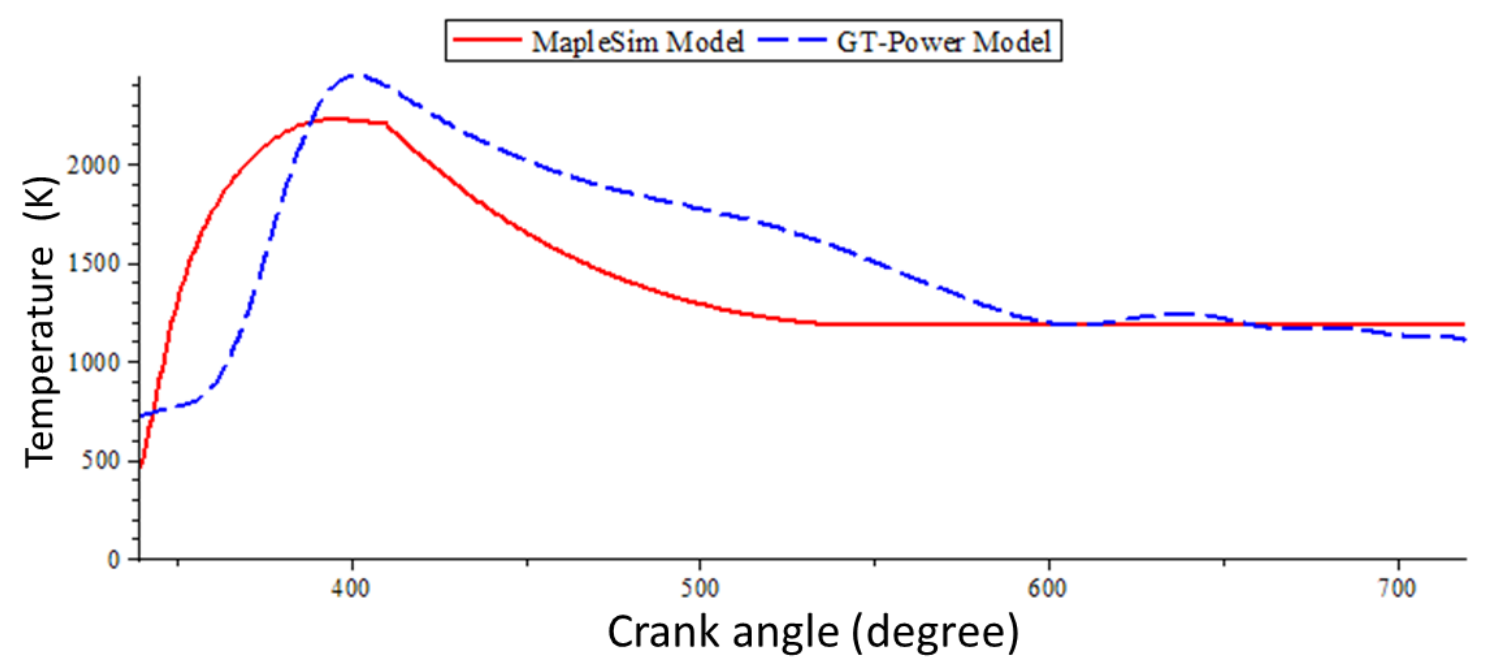

Figure 15: Temperature of burned mixture

The engine torque, which is calculated based on the in-cylinder pressure and volume, is shown in Figure 16. The negative torque during compression and exhaust introduces negative work to move the piston from BDC to TDC to compress the mixture during the compression stroke, or to drive out the exhaust gases during the exhaust stroke. 


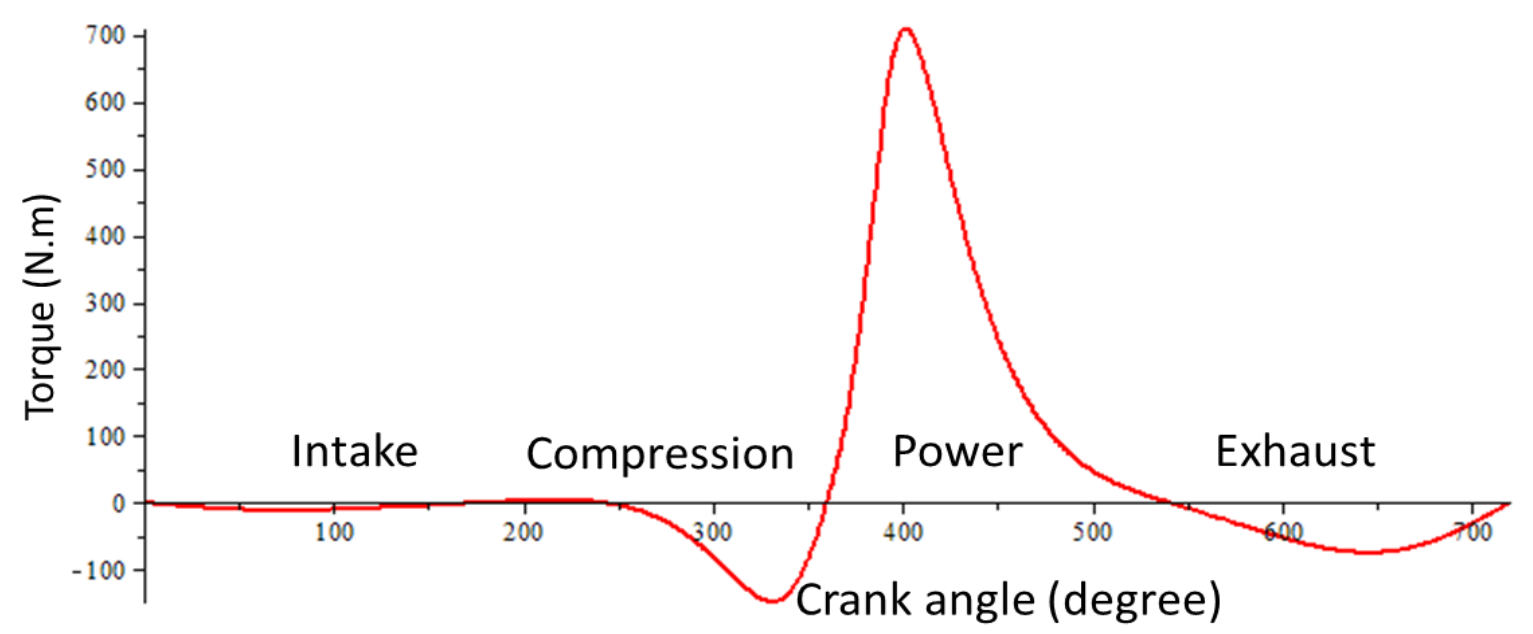

Figure 16: Mechanical/brake torque generated during the four-stroke operation

The proposed model can be used to simulate many simulation cycles with variable spark timing. In other words, the spark timing can be changed at any cycle for control purposes. The crank angle $(\theta(t))$ is used as a criterion to switch from one cycle to the other cycle. Each cycle takes two full rotations of crank, which is equal to 720 degrees. The floor function in Eq. (14) is used to define the start of intake stroke at each cycle, and the start of other strokes (e.g. compression, combustion, expansion, and exhaust) is defined based on the start of the previous stroke. For instance, the simulation starts from zero crank angle $(\theta(t)=0)$ and Start of Intake $(t)=0$, then the whole cycle evolves during 720 degrees. At the end of the first cycle (at $\theta(t)=720^{\circ}$ ), the value of the floor function is one, and the value of Start of Intake $(t)$ becomes 720 . The whole process of four-stroke operation with new inputs (load, engine speed, and air-fuel mixture) is repeated for the new cycle simulation.

Start of Intake $(t)=\lfloor\theta(t) / 720\rfloor \times 720^{\circ}$

Start of Compression $(t)=$ Start of Intake $(t)+180^{\circ}$

Start of Combustion $(t)=$ Start of Compression $(t)+180^{\circ}+S A^{o}(t)$

Start of Expansion $(t)=$ Start of Combustion $(t)+B D^{o}(t)$

Start of Exhaust $(t)=$ Start of Expansion $(t)+180^{\circ}$

End of Exhaust $(t)=$ Start of Exhaust $(t)+180^{\circ}$

The emission sub-model generates the concentration of eleven species in equilibrium, as shown in Figure 17, as well as the solution of chemical kinetic equations (Eq. (8) and (9)) for $N O$ and $C O$ as shown in Figure 18 and Figure 19. The trends of the emission 
gases are similar to the GT-Power simulation results, but the values are not identical. The differences in the in-cylinder pressure and temperature affect the emission variation.

The $N_{2}$ equilibrium concentration has the highest molar fraction value at stoichiometric condition, which is in agreement with the molar concentration of the fresh air in the reactants (Eq. (3)). The $\mathrm{H}_{2} \mathrm{O}$ and $\mathrm{CO}_{2}$ are the next major species in the equilibrium products. The rest of the products have a minor molar fraction contribution in the product as shown in the Figure 17. The emission calculation can be repeated at each cycle with different inputs such as spark timing and air-fuel ratio for many simulation cycles.

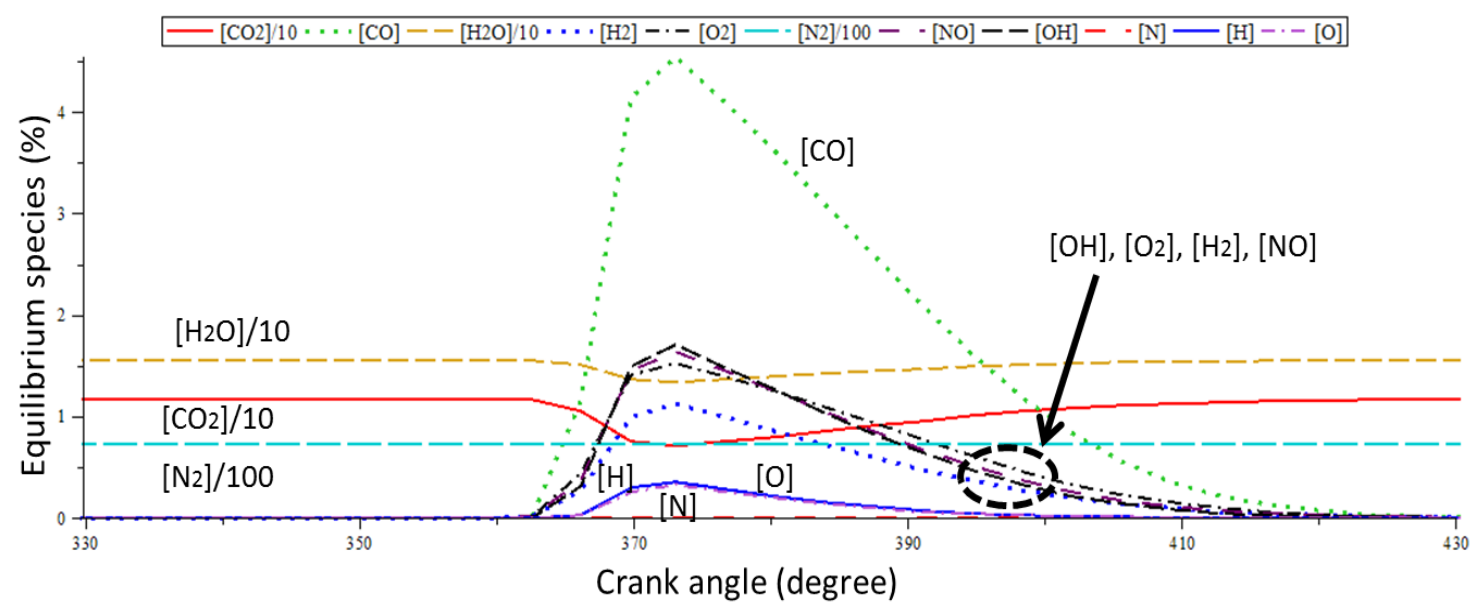

Figure 17: Molar fraction of equilibrium species concentration

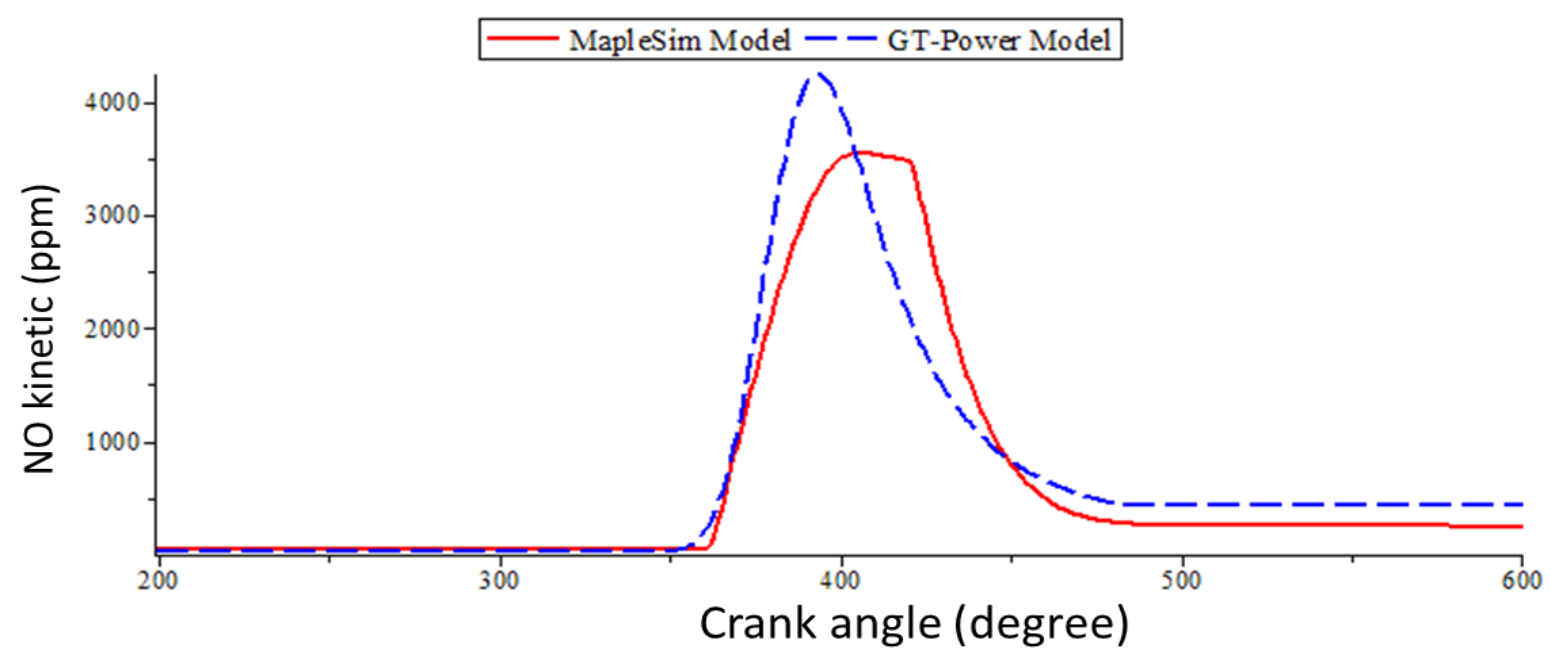

Figure 18: Kinetic NO emission 


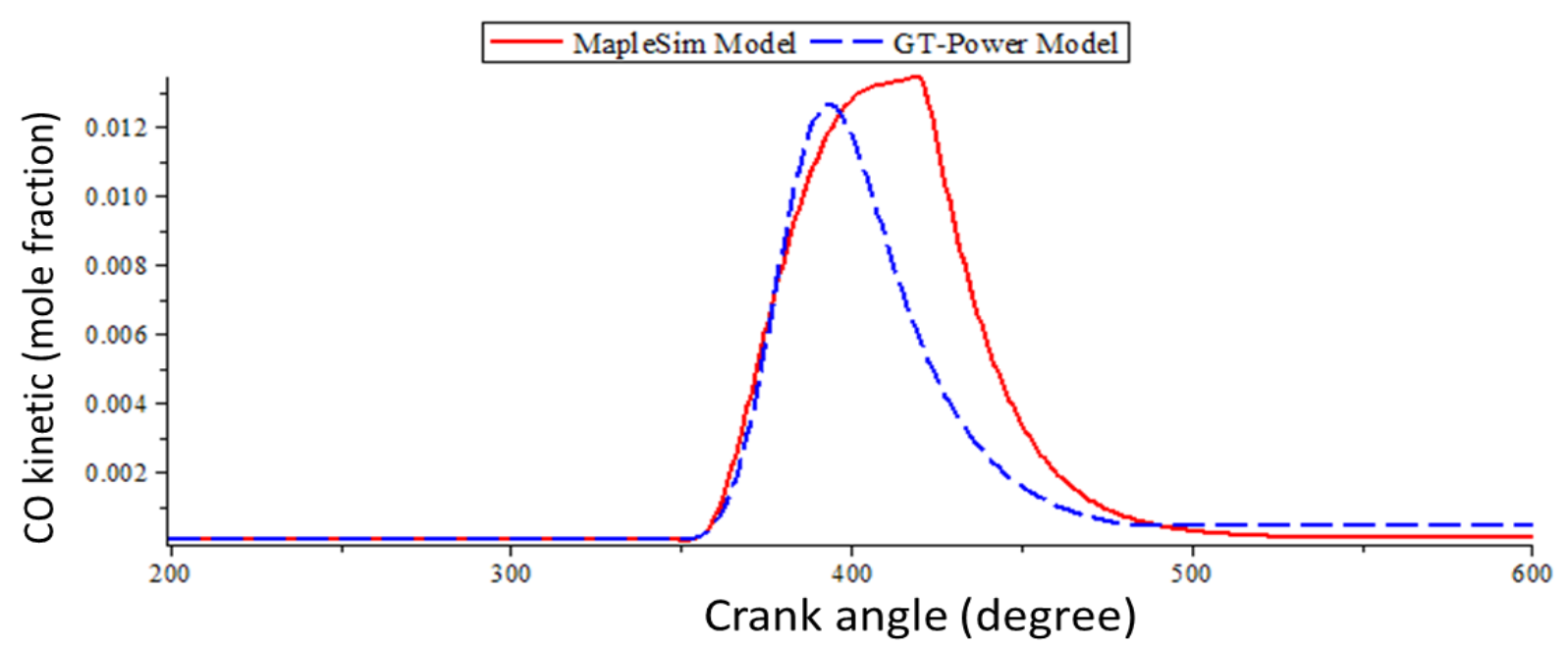

Figure 19: Kinetic CO emission

The simulation time for four-stroke thermodynamic equations with two-zone combustion is faster than real time. The simulations are executed on a 64-bit Windows 7 computer with Intel (R) Core (TM) Duo 3.33 GHz CPU. The simulation time for one cycle at $3000 \mathrm{rpm}$ is about 0.035 seconds, which is faster than real time ( 0.04 seconds).

\section{Conclusions}

In this paper, a math-based spark ignition engine is developed as a plant model for control applications. For this purpose, the quasi-dimensional spark ignition engine modeling approach is accurate enough to generate in-cylinder properties (e.g. pressure, temperature) and consequently emission gases, while the simulation time is fast enough for real time simulation and powertrain control applications.

The main inputs to the proposed model at each cycle simulation are: premixed air/fuel mass, spark advance angle, and engine rotational speed (rpm). The intake, compression, power (combustion and expansion), and exhaust strokes are simulated based on the crank angle variations. The in-cylinder outputs (e.g. pressure, burned temperature, and burned volume) are generated for each cycle, and integrated with the emission submodel to calculate equilibrium and kinetic concentrations. A simple formulation is used to calculate mechanical torque as a function of in-cylinder pressure, volume, and crank angle.

The proposed model is a suitable plant for SI engine control applications such as emission control. Also, by taking advantages of the symbolic nature of MapleSim in 
modeling, a symbolic sensitivity analysis can be easily evaluated to study the effect of the parameters on SI engine performance.

\section{References}

[1] Maplesoft, "MapleSim Applications," 2012. [Online]. Available: http://www.maplesoft.com/Applications/maplesim, accessed Sept. 2012.

[2] M. R. Saeedi, "A Mean Value Internal Combustion Engine Model in MapleSim," Master's Thesis, University of Waterloo, Waterloo, 2010.

[3] B. J. Heywood, Internal Combustion Engines Fundamentals, McGraw-Hill Book Co., 1988.

[4] J. I. Ramos, Internal Combustion Engine Modeling, New York: Hemisphere Pub. Corp., 1989.

[5] P. K. Senecal, J. Xin and R. D. Reitz, "Prediction of Residual Gas Fraction in IC Engines," in SAE 962052, 1996.

[6] N. C. Blizard and J. C. Keck, "Experimental and Theoretical Investigation of Turbulent Burning Model for Internal Combustion Engines," in SAE 740191, 1974.

[7] R. J. Tabaczynski, C. R. Ferguson and K. Radhakrishnan, "A Turbulent Entrainment Model for Spark Ignition Engine Combustion," in SAE 770647, 1977.

[8] R. S. Benson, W. D. Annand and P. C. Baruah, "A Simulation Model Including Intake and Exhaust Systems for a Single Cylinder Four-Stroke Cycle Spark Ignition Engine," International Journal of Mechanical Science, vol. 1, no. 17, pp. 97-124, 1974.

[9] P. N. Blumberg, G. A. Lavoie and R. J. Tabaczynski, "Phenomenological Models for Reciprocating Internal Combustion Engines," Journal of Energy Combust Sci., no. 5 , pp. 123-167, 1979.

[10] H. Bayraktar, "Mathematical Modeling of Spark Ignition Cycle," Journal of Energy 
Sources - Recovery, Utilization and Environmental Effects, pp. 651-666, 2003.

[11] H. Bayraktar and O. Durgun, "Theoretical Investigation of Using Ethanol-Gasoline Blends on SI Engine Combustion and Performance," in International Conference on Thermal Engineering and Thermogrammetry, Budapest, 1997.

[12] S. Verhelst and C. G. Sheppard, "Multi-zone Thermodynamic Modeling of Spark Ignition Engine Combustion - an Overview," Journal of Energy Conversion and Management, vol. 50, no. 5, pp. 1326-1335, 2009.

[13] S. Sitthiracha, "An Analytical Model of Spark Ignition Engine for Performance Prediction," Master's Thesis, King Mongkat's Institute of Technology North Bangkok, Thailand, 2006.

[14] C. E. Newman, C. Newman, J. J. Batteh and M. Tiller, "Spark Ignited Engine Cycle Simulation in Modelica," in 2nd International Modelica Conference , 2002.

[15] H. Bayraktar and O. Durgun, "Development of an Empirical Correlation for Combustion Durations in Spark Ignition Engines," Journal of Energy Conversion and Management, vol. 45, no. 9, pp. 1419-1431, 2004.

[16] A. Balluchi, L. Benvenuti, C. Lemma, P. Murrieri and A. L. SangiovanniVincentelli, "A Cycle Accurate Nonlinear Hybrid Model of SI Engine for the Idle Speed Control," Internal Technical Report, PARADES, Rome, 2004.

[17] S. R. Turns, An Introduction to Combustion, Concepts and Applications, McGrawHill Series in Mechanical Engineering, 2000.

[18] I. Arsie, C. Pianese and G. Rizzo, "Models for the Prediction of Performance and Emissions in a Spark Ignition Engine - A Sequentially Structured Approach," in SAE 980779, 1998.

[19] M. S. Al-Baghdadi and H. A. Al-Janabi, "Improvement of Performance and Reduction of Pollutant Emission of a Four Stroke Spark Ignition Engine Fueled with Hydrogen-Gasoline Fuel Mixture," International Journal of Energy 
Conversion \& Management, vol. 41, pp. 77-91, 2000.

[20] J. Banerjee, H. Adibi-Asl, N. L. Azad and J. McPhee, "Parametric Importance Analysis and Design Optimization of a Torque Converter Model Using Sensitivity Information," SAE International Journal of Passenger Cars - Mechanical Systems, vol. 5, pp. 621-638, 2012. 